\title{
AUTOVÍAS: NOS OLVIDAMOS DEL PAISAJE
}

\section{(HIGH-ROADS: OMISSION OF LANSCAPE)}

\author{
Antonio López Lillo, Dr. Ing. de Montes. \\ Jefe del Servicio del Medio Natural, Comunidad de Madrid. ESPAÑA
}

\section{RESUMEN}

Se hace mención a la gran labor que se está desarrollando para aumentar y mejorar la red viaria. Se denuncia que la forma de realizarla está produciendo un grave deterioro al medio natural, en muchos casos irreversible.

Se hace un análisis de la situación, a la vez que se repasa la problemática que se plantea en las diversas fases que componen la realización de estas grandes obras públicas.

Se alude a diversas circunstancias: excesiva premura en la realización; planificación sin tener en cuenta las condiciones del medio ambiente; incorrecta e ilegal aplicación de la normativa de evaluación de impacto ambiental; ejecución de la obra con total desprecio al medio natural, con daños añadidos a los inherentes a esa obra; escasos o nulos trabajos de restauración y mejora del entorno impactado; desconsideración con la integración de la obra en el paisaje; falta o inadecuado proyecto de mantenimiento y conservación de las áreas a regenerar si es que existen.

Se apuntan posibles medidas para paliar o evitar los daños; estudio de alternativas respetuosas con el medio natural; redacción de un proyecto integrado que considere la naturaleza en su verdadero y justo valor; rigurosidad en la ejecución y vigilancia de las obras; realización de proyectos serios de restauración del medio natural deteriorado; establecimiento de planes de mantenimiento y seguimiento de las áreas restauradas.

Se llama la atención con el fin de aprovechar la ocasión para realizar obras bien hechas, respetuosas con la naturaleza y que logren su mejora.

\section{SUMMARY}

In the present work is mentioned the great task that it is realizing to improve and to increase the road net. It is advised like the programm is accomplished with a serious injury for nature, sometimes irreversible.

The situation is analized and the question is examined in the different phases of these great public works.

The different circumstances are suggested: unreasonable pressure in the achievement; project without environment consideration; wrong environment impact evaluation; perfomance's achievement with total neglect for nature; poor works of the restoration and improvement of the deteriorated area; disregard with integration of the work into the landscape; deficient or inadequated conservation plan of the area to restore.

Possible solutions are insinuated to palliate or to avoid the damages: study of respect full nature options; redaction of a integrated project with consideration with nature; severity in performance and control of the works; realization of serious restoration projects; preparation of conservation plans.

It is called attention to take occasion to realize well made works, respectables with nature and that improve the environment.

\section{ANÁLISIS DE LA SITUACIÓN}

Estamos viviendo unos años de desenfrenado desarroIlo viario. Basta recorrer cualquier parte del territorio español por recóndito que sea, y será dificil encontrar algún lugar, o en su entorno, donde no se aprecie la huella de lo que se llama mejora de la red de comunicaciones por carretera. Se puede "admirar" desde grandes obras para crear autovias, desdoblar calzadas, mejorar tramos hasta variaciones del trazado en la red secundaria e incluso terciaria.

Por fin, nos hemos dado cuenta de que nuestro entramado de vias de comunicación no era acorde con los

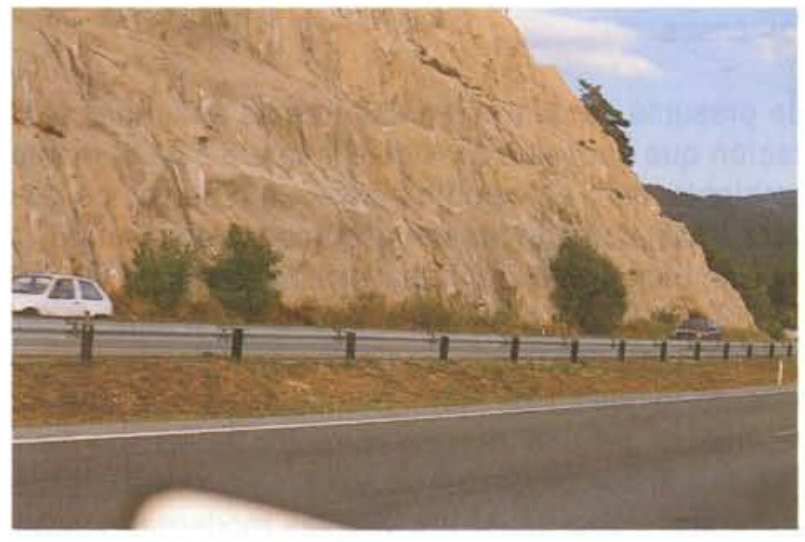

Nacional VI. 


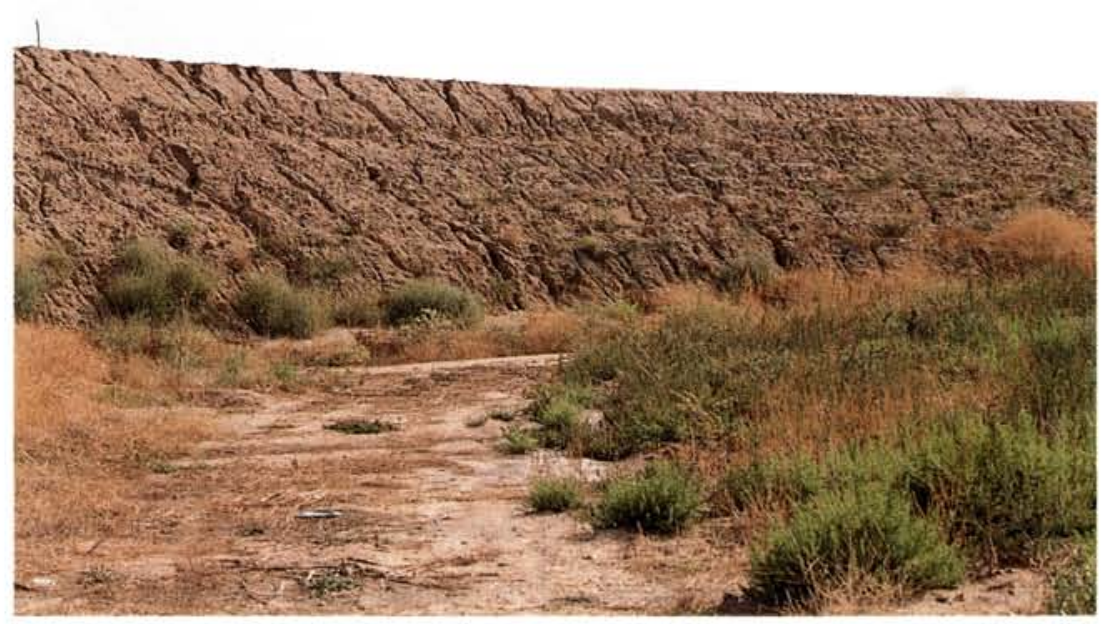

Erosión incipiente al borde de la carretera.

tiempos de la Europa comunitaria. No solamente nos hemos lanzado sobre nuestras carreteras, sino que también queremos desarrollar los trenes de alta velocidad (TAV), que a mi juicio deberiamos llamar de "alta precipitación", pues pienso que una obra de tal envergadura necesitaba mayor previsión y mayor meditación, asi como un gran debate para considerar su conveniencia.

Se está realizando un gran esfuerzo financiero para salir de ese atraso, se dedican fondos de todo tipo, desde los presupuestos del Estado hasta los de las Comunidades Autónomas, sin olvidar la importante ayuda que supone la Comunidad Económica Europea a través del FEDER.

Pero lo mismo que existe unanimidad en realizar inversiones para intentar adecuar la red de comunicaciones a la del resto de Europa, también parece que hay conjunción de criterios en el momento de llevar a cabo esta política, en relación al tratamiento que se da al medio natural. Es como si se hubiera dicho "carreteras y trenes de alta velocidad ante todo y sobre todo", con absoluto desprecio al medio ambiente en la mayoria de los casos.

Se presume de que nos encontramos ante una civilización que cada vez considera y valora más el medio ambiente, pero en cambio se ejecutan proyectos que deterioran el medio natural iy cómo lo deterioran! Como también nos encontramos en la época de las prisas, todo tiene que estar hecho para una fecha determinada, generalmente sin disponer del tiempo suficiente, lo que añade mayor perjuicio al medio ambiente, que si precisa de una duración adecuada para desarrollar sus procesos. La realización de estas grandes obras necesita de tecnologías modernas y avanzadas que utilizan enormes maquinarias y procedi- mientos grandiosos, que recuerdan a cataclismos de tiempos prehistóricos, remedando las máquinas a animales antidiluvianos. Estamos abocados a pasar por un determinado paraje y que alguien nos diga ¿os acordáis de aquel maravilloso paisaje que se contemplaba desde aqui? pues ahora con esta moderna autopista se llega antes, pero ya apenas se aprecia.

Creo que se está desperdiciando una magnifica ocasión, pues se podria aprovechar el momento para que este avance en la red viaria supusiera también una mejora para el paisaje. Esta época deberia pasar a la posteridad, no sólo como la del desarrollo viario, sino como la de las obras bien hechas, que consideraron de una forma adecuada el paisaje, el medio natural por el que transcurrian, logrando la integración en él, mejorándolo en algunos aspectos e incluso aprovechando la ocasión para propiciar su restauración al atravesar áreas degradadas.

\section{PROBLEMÁTICA}

La indiferencia hacia el medio ambiente se observa ya en la fase de planificación y proyecto, continúa en el momento de ejecutar las obras, persiste en su finalización y se olvida una etapa posterior que estudiase la perturbación ocasionada.

\section{Fase previa}

Se planifica sin tener en cuenta, o solamente de forma muy somera, el medio natural sobre el que va a rea. lizarse la obra. Muchas veces parece como si el trazado se hubiera marcado sobre los planos en un gabinete de estudios, sin ir al terreno, utilizando únicamente ma. http://informesdelaconstruccion.revistas.csic.es 


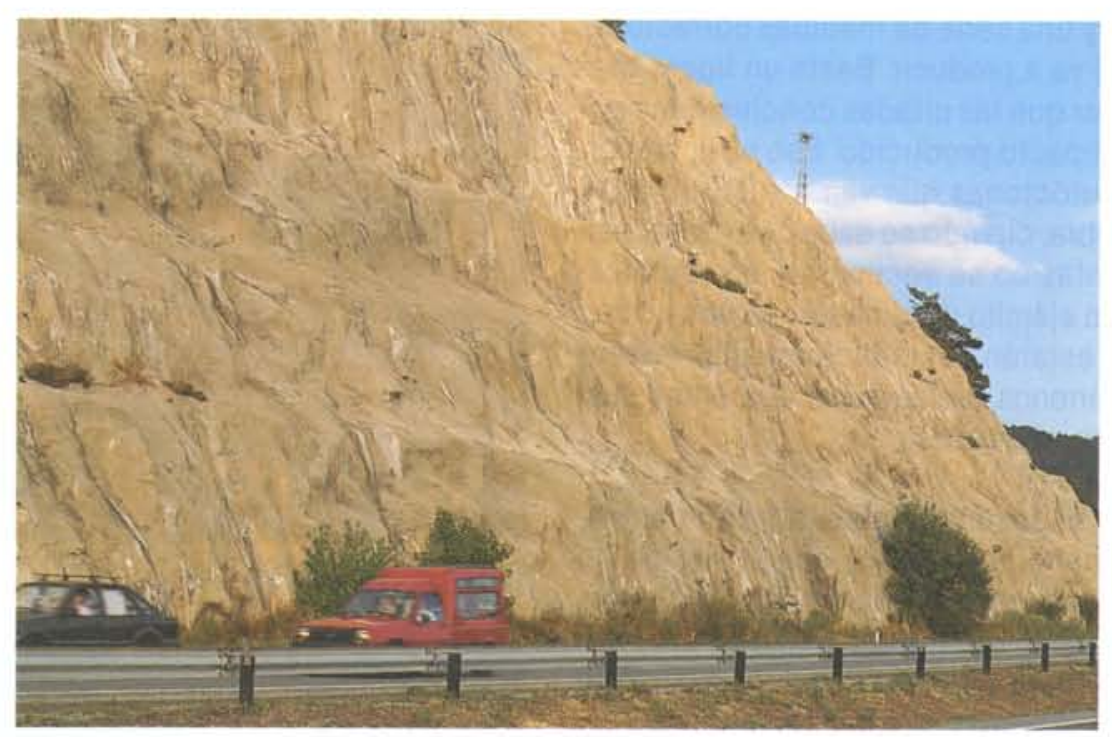

Falso remedio sobre la naturaleza. Cemento sobre rocas.

pas topográficos cuando, en general, se dispone de cartografia temática indicadora de las caracteristicas del medio. Hay casos en los que parece que se han buscado los espacios de mayor valor ecológico para proyectar por ellos el trazado. Pero no solamente se deteriora el medio natural, sino que también se destruyen fincas que mantienen especies foráneas de gran valor, o por su longevidad o por su singularidad, y que pueden significar una importante mancha verde en la zona.

Se intuye que se ha buscado la sencillez siguiendo lineas de fácil construcción a expensas de arruinar o destruir valores que han precisado años, incluso siglos, para llegar a su estado actual, y todo ello simplemente por unas ideas surgidas en un gabinete de estudios. Se eliminan muchos años de naturaleza en la mayoria de los casos de forma irreversible; se da a entender que el fin justifica los medios.

Cuando se muestra preocupación por el daño que se va a cometer, o se está cometiendo, en muchos casos se advierte como se bordea la legalidad vigente. Se desprecian normativas legales de obligado cumplimiento, alegando la urgencia en la realización de las obras. Es fácil olvidar la Ley de Montes, la Ley de Vias Pecuarias, Ia Ley de Conservación de Espacios Naturales, su fauna y su flora, etc., o bien no se siguen las normas de Evaluación de Impacto Ambiental, o no se respetan los plazos establecidos soslayándoles con normas de planificación, aludiendo a las prisas.

Precisamente los estudios de Evaluación de Impacto Ambiental (E.I.A.) merecen que les dediquemos unos párrafos especiales.

Desde que apareció este instrumento legal, cuyo valor

(c) Consejo Superior de Investigaciones Científicas

Licencia Creative Commons 3.0 España (by-nc) es innegable, parece como si se hubiera encontrado la justificación a muchos desaguisados. Se decide un trazado y después se encarga al E.I.A., pero para que apoye y justifique ese trazado. De esta manera se tranquilizan conciencias; es como un mero trámite para explicar la situación, es como la obsoleta póliza que faltaba para llevar a cabo la obra.

Cuando se muestra interés por analizar el E.I.A. aparecen uno o varios grandes tomos, muy bien presentados, que abarcan una gran extensión como si el estudio se valorara por su peso. Pero basta hojear el trabajo para comprender su alcance; páginas y páginas de datos meteorológicos, eso sí, de estaciones distantes a la obra, pues es dificil que se encuentre alguna estación meteorológica en las cercanias. Se encuentran inventarios fitosociológicos de asociaciones y formaciones vegetales sobre los que se va a desarrollar la obra co. piados de las publicaciones existentes de los más afanados botánicos, generalmente mal transcritos (cada vez se conoce menos el inestimable latin). Aparecen listados de suelos con su composición y su interés, bien obtenidos de las calicatas precisas para cimentar los trabajos o bien simplemente extraidos de las mo. nografias de las cartografias temáticas publicadas. Asi se podria seguir hojas y hojas rellenas de datos zoológicos, geológicos, paisajisticos; en fin, de todas las disciplinas que dan a conocer el medio natural sacados de las publicaciones existentes. Total, un mayúsculo mamotreto de datos ya conocidos y leidos con anterioridad poco originales, siguiendo autores de renombre, adornados con esquemas, dibujos, figuras, fotografias, mapas que decoran los antedichos temas. Por último, aparecen unas raquíticas conclusiones que, teniendo en cuenta apenas todo lo escrito, avalan la bondad del proyecto y lo justifican, aconsejan una serie de actuaciones en áreas de una escrupulosidad con 
el medio existente y una serie de medidas correctoras del impacto que se va a producir. Basta un ligero examen para comprobar que las citadas conclusiones poco van a paliar el impacto producido. Eso sí, aparecen listas de plantas autóctonas que van a sustituir a las eliminadas por la obra, cuando se sabe que es imposible, pues tales plantas no se encuentran en el mercado. Seguramente, un ejército de cipreses, cedros y otras especies exóticas estarán esperando en algún vivero para colonizar los terrenos asolados por las obras y sustituir a las especies eliminadas.

Cuando se expone lo poco útil del estudio en comparación con su apariencia, se indica que el equipo de la consultora "ad hoc" es multidisciplinar (biólogos, geólogos, ingenieros de montes, paisajistas, etc.), como si la titulación fuera una justificación, cuando lo que se precisa son expertos en tema tan especial como el manejo del medio natural, titulados adecuados pero que conozcan de una forma práctica los procesos integrados que se producen en la naturaleza y tengan experiencia en ecología aplicada.

\section{Fase de ejecución}

Al no existir una adecuada planificación respetuosa con el medio natural, es dificil pretender que la ejecución se desarrolle de forma exquisita con el medio, siendo en esta fase donde se pueden producir gran. des deterioros en muchos casos innecesarios, o por lo menos evitables, al no tener nada que ver con el proyecto de la obra.

Como no se han establecido los itinerarios de las grandes máquinas, éstas campan por sus respetos, destruyen plantas, hábitat, etc., pues ocupan lugares fuera de proyecto, estableciéndose los parques de maquinaria donde parece mejor para la obra, ignorando el medio natural. Los camiones circulan por doquier, destruyendo con sus grandes neumáticos plantas, compactando suelos, propiciando erosiones, deteriorando troncos y ramas con sus descomunales volúmenes, abren caminos de anchura innecesaria como si dispusieran de todo el entorno de la obra.

Se depositan y almacenan sobre los aledaños a los trabajos los materiales a utilizar, siempre de la manera más cómoda y fácil, con total desprecio a la naturaleza y con el consiguiente perjuicio.

Como cualquier obra de esta envergadura, o se precisan aportes de tierras o se necesita evacuarlas, ello se hace de la forma más sencilla. Es fácil apreciar en las proximidades grandes áreas degradadas que atentan al paisaje, ocasionadas por la extracción de tierras. Muchas veces se realizan $\sin$ los oportunos permisos que se precisan, y cuando se quieren evitar nos encontra-

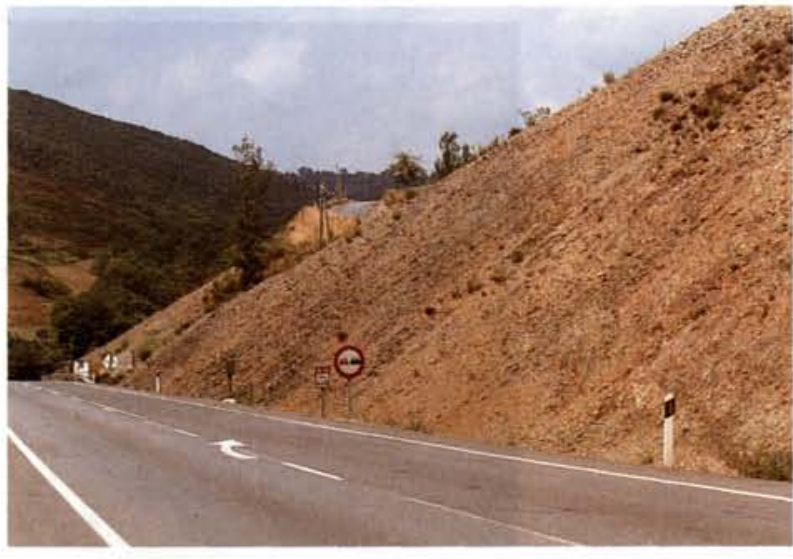

Ta1ud a la espera de la erosión.

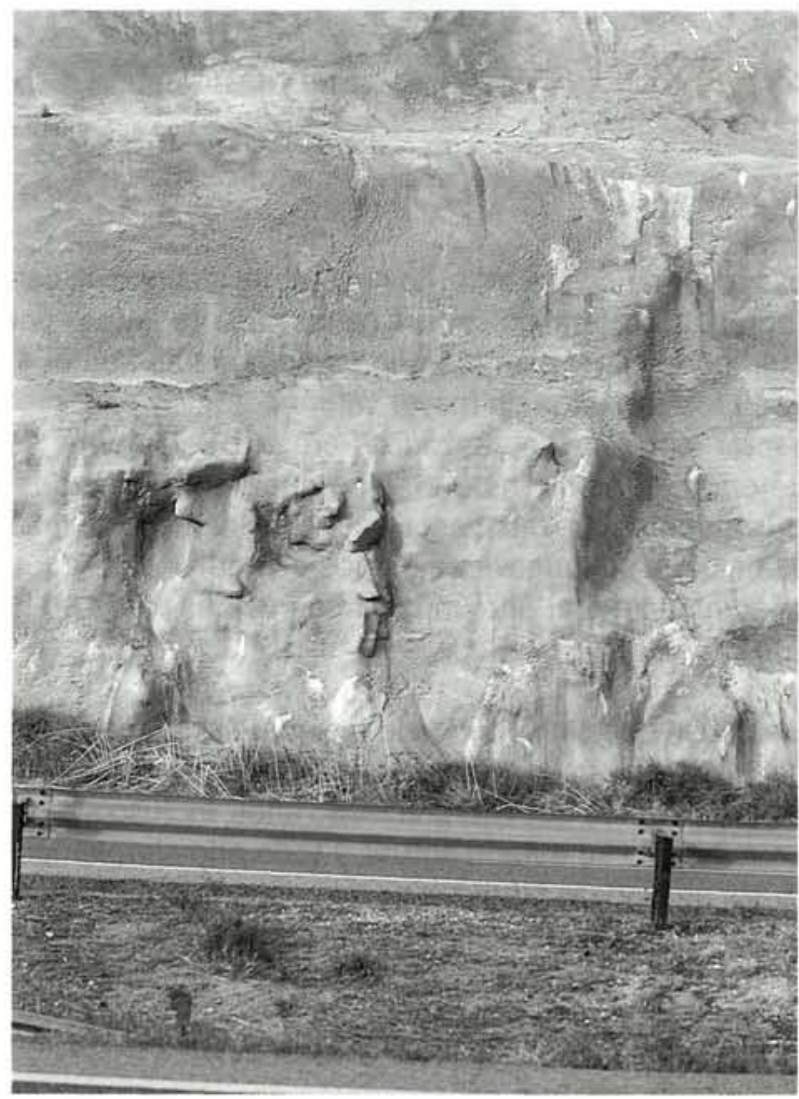

¿Naturaleza o cemento?

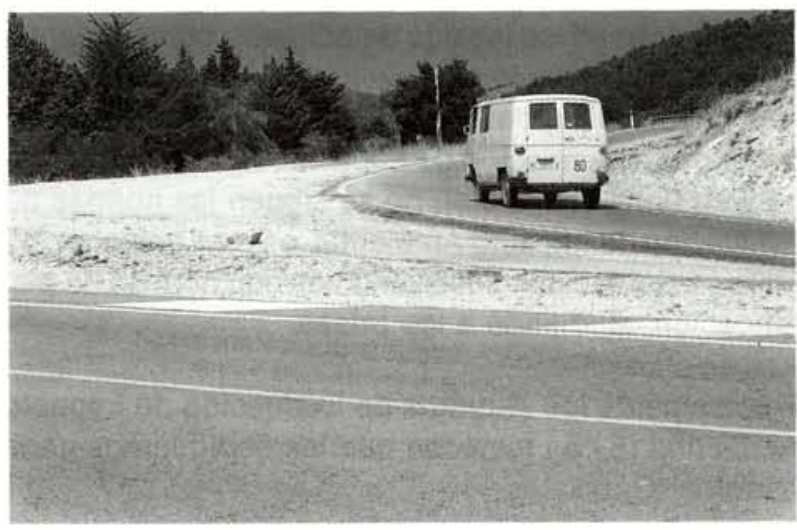

Forma de acabar enlaces.

http://informesdelaconstruccion.revistas.csic.es 


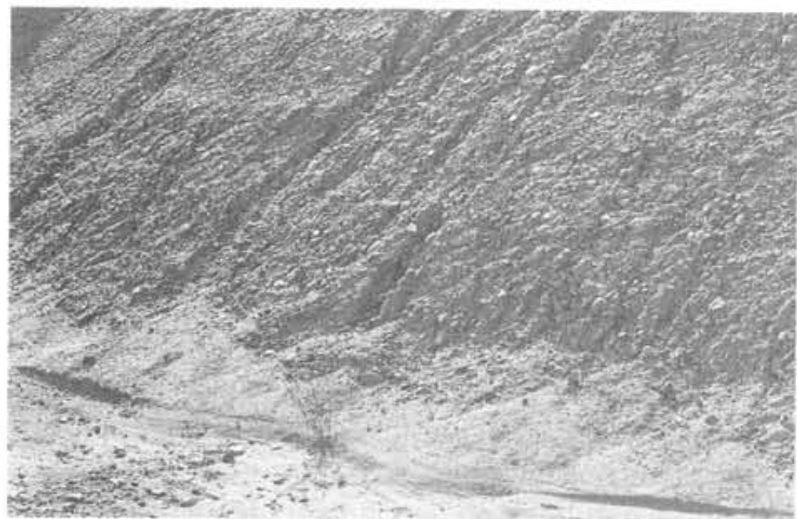

¿A dónde van las tierras?

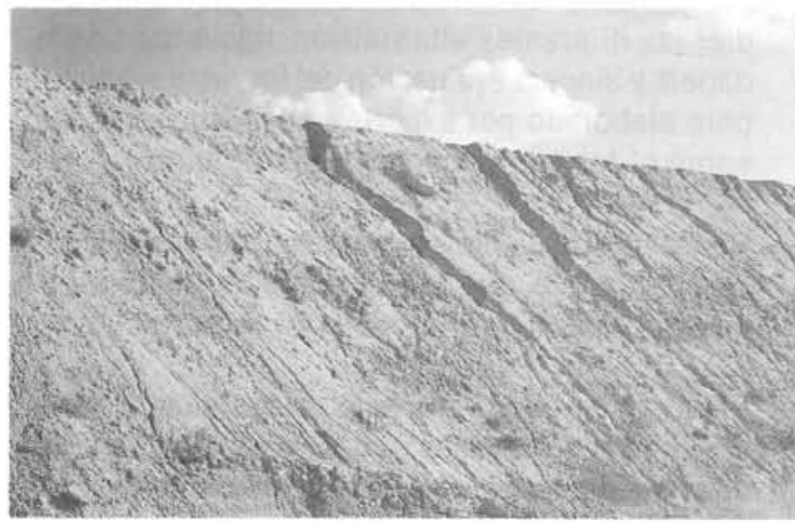

Sigue la erosión.

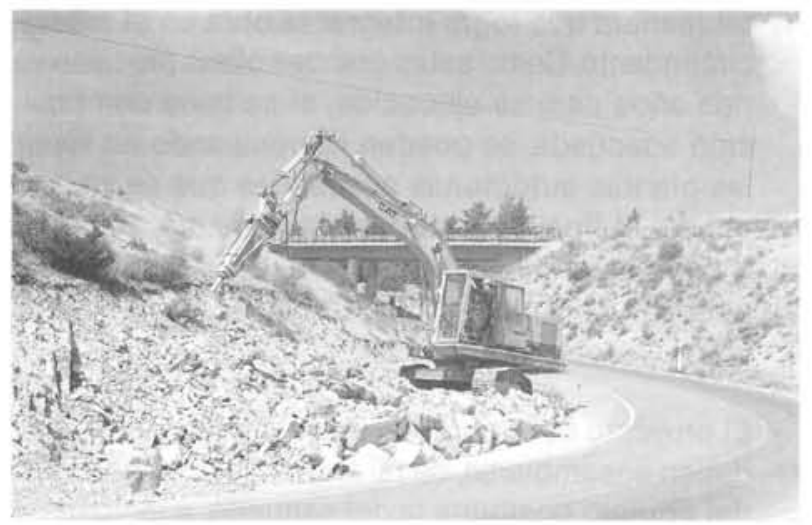

Las grandes máquinas favorecen el proceso.

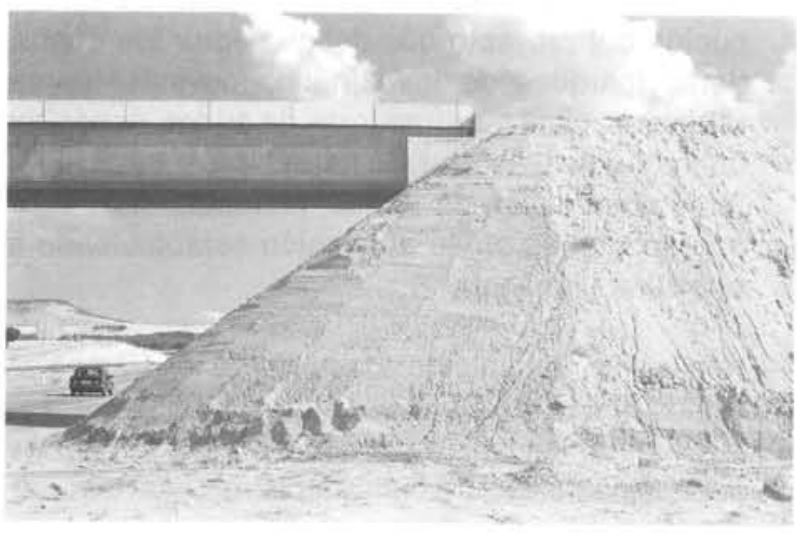

¿Dónde están las plantas?

(C) Consejo Superior de Investigaciones Científicas Licencia Creative Commons 3.0 España (by-nc) mos ante un hecho consumado. Igualmente, si sobran tierras éstas se depositan en cualquier zona próxima a las labores aplastando, cubriendo o eliminando elementos del medio natural y también, generalmente, sin las licencias preceptivas.

Los materiales de desecho o sobrantes de la obra se abandonan por cualquier parte con el consiguiente perjuicio. Restos de hormigones, asfaltos, alquitranes, gravas, etc., se encuentran esparcidos por doquier, alterando el medio natural, elementos en general de difícil integración con ese medio.

Las grandes plantas machacadoras de áridos precisas para este tipo de trabajos se colocan en la parte más cómoda para la obra, sin considerar si es el lugar más adecuado desde el punto de vista natural. Es fácil comprobar en las cercanias de estos complejos grandes daños al medio natural. Las grandes nubes de polvo ocasionan gran mortandad de plantas y animales. Cuando los trabajos han finalizado se abandonan sin reconstruir el lugar, asemejándose a un pueblo abandonado del Oeste americano.

Los nuevos trazados llevan a veces al abandono de tramos antiguos, sin considerar que es muy dificil su degradación y posterior integración con el medio. ¡Qué fácil seria que la gran maquinaria utilizada eliminara estos espacios o se transformaran en lugares de acogida u ocio de los automovilistas!

Se podria alargar esta lista de daños, pero la muestra es suficiente para llamar la atención sobre la importan. cia que tiene esta fase en la preservación del medio natural.

Muchos de los perjuicios ocasionados no son solamente achacables a la Administración, sino a la comodidad de contratistas que, por otra parte, no son vigilados adecuadamente por esa Administración y, en particular, sobre su comportamiento con la naturaleza.

\section{Fase última}

Cuando ya se aborda la fase final de la obra empieza a asomar un atisbo de restauración vegetal que, en la mayor parte de los casos, habria que llamar disfraz verde, color simbólico que a veces se utiliza (y no siempre) para pintar grandes placas de cemento que cubran las áreas degradadas.

Suponiendo que se haya previsto algún tratamiento con plantas dentro de los dias cercanos a la inauguración, son traidas grandes cantidades de plantas para deco. rar y cubrir las áreas que deja al descubierto la obra y que podrian recordar a los suelos del desierto. Se hacen unas plantaciones raquiticas con especies exóti- 


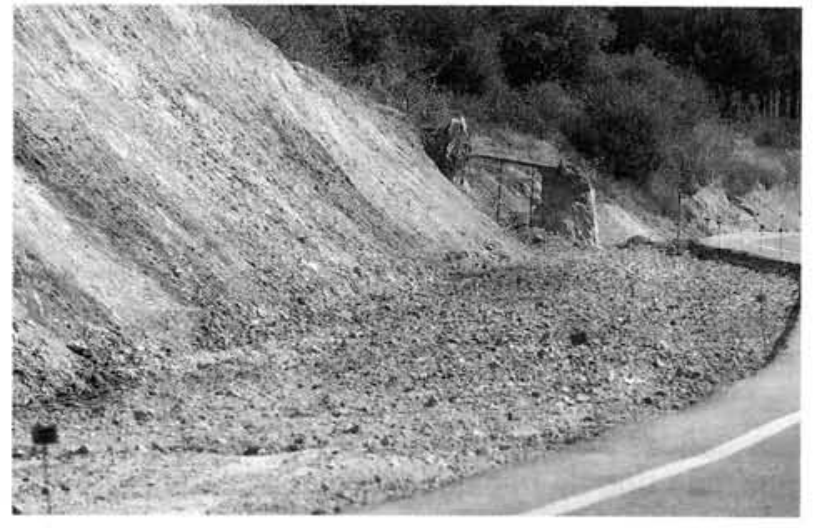

El arcén merece un mejor tratamiento.

cas, pareciendo que únicamente se busca la presencia para el momento de la inauguración. Alguna vez se utilizan plantas autóctonas de las existentes en el mercado, pero que sería una coincidencia se parecieran a las propias del lugar. Además, se colocan de cualquier forma, sin un previo estudio de su localización más ade. cuada. En algún caso, y con mayor tiempo, se realizan semillados buscando que una pradera dé un color verde a la obra.

En el caso de que exista un proyecto de restauración, más bien un mini-proyecto, siempre se basa en un proyecto de repoblación forestal o en uno de creación de zonas verdes. Por supuesto, nunca en un proyecto pensado para restaurar ese medio natural perturbado, por lo que ni considera las plantas adecuadas, ni contem. pla los procedimientos necesarios, ni ha preparado el suelo convenientemente. Es fundamental tener en cuenta que las plantas autóctonas deben ser los principales actores protagonistas y no los meros espectadores del drama consumado.

También es fácil que exista un proyecto serio del mantenimiento de ese sucedáneo de restauración verde. Es corriente al recorrer tramos de carreteras de reciente inauguración, a los pocos dias, apreciar restos vegetales de las especies plantadas o praderas perdidas por la falta de los cuidados adecuados. Si pasa más tiem. po se pueden contemplar o fases de erosión incipiente $\mathrm{o}$, incluso, erosiones de consideración en taludes y terraplenes.

Se puede tachar todo lo anterior de catastrófico, pero esto es lo que ocurre la mayoría de las veces. No obs. tante, existen excepciones de obras que han considerado algo más el acabado vegetal, como en algunas autopistas de peaje. Pero de todas maneras sin el rigor que se requiere para este tipo de proyectos de restauración del medio natural.

\section{MEDIDAS POSIBLES}

A mi juicio si se quiere hacer este tipo de obras con la seriedad que merece la naturaleza habria que actuar de la siguiente manera:

- Cuando se ha decidido realizar una obra de esta envergadura sobre un territorio, hay que tener muy claro cuáles son las zonas de ese territorio que por sus valores naturales no pueden ser utilizadas. Una vez que se ha situado el trazado sobre el resto de las zonas, hacer las visitas de campo precisas y estudiar las diferentes alternativas, haciendo una verdadera y sincera evaluación del impacto ambiental, pero elaborado por expertos que toman los datos sobre el terreno y los sepan interpretar.

- Redacción de un proyecto que tenga en cuenta, desde el principio, que hay que integrar la obra en el paisaje y permita una posterior restauración.

- Elaboración de un proyecto de restauración, pero un verdadero proyecto, que tenga en cuenta que se quiere restaurar un determinado medio natural, acudiendo a los elementos de ese medio sin emplear otros, o bien únicamente de forma transitoria, de tal manera que logre integrar la obra en el paisaje circundante. Como estas grandes obras precisan varios años para su ejecución, si se hace una previsión adecuada, se pueden ir preparando en vivero las plantas autóctonas necesarias que se vayan a utilizar al final de las obras. Igualmente, se deben ir considerando las tierras que van a ser precisas para que esas plantas dispongan del suelo adecua. do.

- El proyecto de la obra y el proyecto de restauración deben ensamblarse, de tal manera que la ejecución del primero posibilite la del segundo, e incluso ha. cerlos simultáneos donde se pueda.

- Elaboración de unas normas muy rígidas para la ejecución del proyecto que deban seguir los contra. tistas (parques de maquinaria, movimientos de vehículos, plantas trituradoras de áridos, depósitos de materiales, aportes de tierras, préstamos, aportes y eliminación de tierras, residuos, etc.). $Y$ ser muy exigentes en su aplicación estableciendo la oportuna vigilancia.

- Realizar un tratamiento adecuado de los tramos an tiguos que haya que abandonar, o bien proceder a su eliminación para crear una restauración natural sobre su ubicación, o bien adecuarlas para que puedan ser utilizadas para un uso social. 
- El proyecto de restauración y de integración en el medio debe ser un proyecto continuo, es decir, que abarque varias fases. La primera fase debe establecer las bases para que mediante etapas masivas se llegue a la definitiva reimplantación del medio natural, ya que para ello se precisan realizar diferentes actuaciones a lo largo del tiempo, puesto que los elementos utilizados son vivos y dinámicos, ante casi la inmutabilidad de la obra civil.

- Será necesario establecer un plan de mantenimiento y seguimiento para comprobar como se va logrando la restauración. Esto a la larga impondrá un ahorro, pues una vez que se vaya consolidando el medio natural, no habrá que realizar apenas gastos de conservación.

- Si la obra va a pasar por zonas ya muy degradadas o alteradas, se podría aprovechar la ocasión para que con el plan de restauración se reconstruyeran esos antiguos ecosistemas en las áreas de influen. cia de la obra.
- Cuando se realizan las ocupaciones necesarias para llevar a cabo las obras, se podría considerar una superficie más amplia, una, dos o tres veces mayor, según el valor de los terrenos, para establecer unas bandas boscosas a lo largo de la red de comunicaciones que, por una parte, ampliarian las superficies arbóreas y, por otra, mitigarian las contaminaciones que siempre se producen en el entorno de las autovías.

- Si se analizan monetariamente todas las medidas expuestas se podrá comprobar que sus costes son muy pequeños para el conjunto de miles de millones que se invierten en estas grandes obras.

- Si se adoptaran estas medidas se podria presumir que nuestras vias de comunicación están bien hechas, bien acabadas y que no solamente cumplen su papel, sino que han ayudado a mejorar y conservar nuestro deteriorado medio natural y, en definitiva, el paisaje.

\title{
publicación del ICCET/CSIC
}

\author{
INSPECCION DE OBRAS DAÑADAS \\ POR CORROSION DE ARMADURAS
}

El presente Manual va dirigido principalmente a técnicos especializados y laboratorios que tienen que intervenir en el dictamen de la situación de deterioro de estructuras de hormigón armado dañadas por corrosión de armaduras.

Comienza con un resumen recordatorio de los factores principales a los que se pueden deber los daños prematuros por corrosión de armaduras, para seguir con algunas indicaciones de cómo se deben realizar las inspecciones, y de los ensayos y la metodología que se recomienda realizar para poder dictaminar con precisión las causas de daño.

A continuación se hacen una serie de comentarios sobre la vida residual de estructuras dañadas, sobre el riesgo de corrosión futura, el seguimiento necesario de una estructura reparada y una breve enumeración de métodos de reparación y consideraciones básicas a tener en cuenta en la recomendación de un determinado método. Se aporta una breve relación bibliográfica.

Finalmente se incluyen en forma de ficha la descripción de algunos casos de corrosión de armaduras detectados en nuestro país.

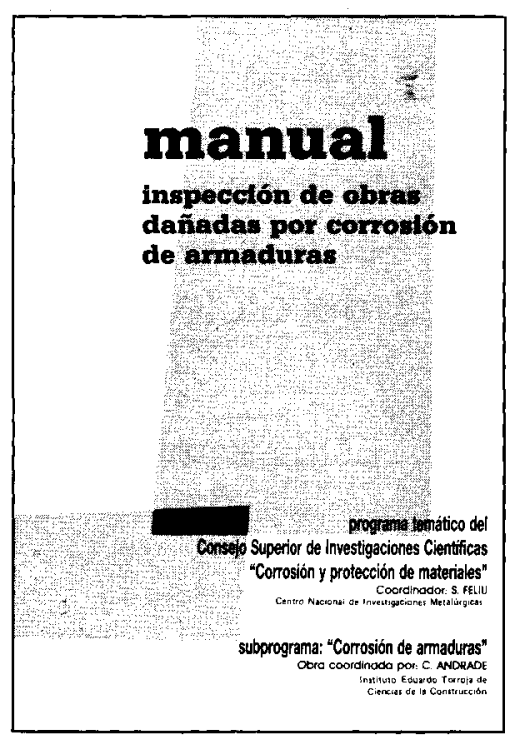

